\author{
Military Technical College \\ Kobry Elkobbah, Cairo, \\ Egypt.
}

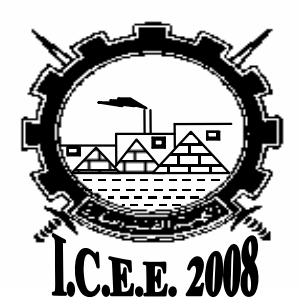

$4^{\text {th }}$ International Conference On Chemical \& Environmental Engineering

27-29 May 2008

\title{
CHEMO-AND BIOSENSOR SYSTEMS FOR SAFEGUARD AND ENVIRONMENTAL CONTROL IN EGYPT
}

\author{
HASSAN AZAB IBRAHIM*
}

\begin{abstract}
The main objective of the project is to establish sensor knowledge, technology and equipment to provide safeguard for Egyptian population and environment in case of accidents or pollution with chemically or biologically hazardous. We will develop lanthanide luminescence sensor systems that will comprise chemosensors and a wipe test for trace amounts of explosives and supramolecular luminescence sensors for pesticides using $\mathrm{Eu}(\mathrm{III})$ and $\mathrm{Tb}$ (III)-ligand complexes for signaling in a sensor array microplate. The pesticide sensors based on moleculary imprinted polymers using our $\mathrm{Eu}(\mathrm{III})$ and $\mathrm{Tb}$ (III) complexes are intended for environmental control of soil, drinking water and foodstuffs. Many pesticides and herbicides are susbected to cause multiple types of cancers. In view of these properties herbicides and pesticides are attractive substances for abuse in different criminal accidents as those substances and their metabolites enter natural waters, soil and food and can cause serious problems for environmental safety and human health when spread around. We will develop a wipe test to detect trace amounts of the most important classes of explosives(aromatic nitrocompounds, and organic peroxides like TATP and HMDT).Determination of trace amounts of explosives will be very important in forensic investigations.
\end{abstract}

\footnotetext{
${ }^{*}$ Chemistry department, faculty of science, Suez Canal university, Ismailia, Egypt
} 